\title{
Design Science Applied to the Virtual Support Method of the Nurse to Promote Mental Health for the Elderly and Their Caregivers
}

\author{
Renata Jabour Saraiva ${ }^{1,}$, , Geilsa Soraia Cavalcanti Valente ${ }^{2}$, Selma Petra Chaves Sá2 \\ Ann Mary Machado Tinoco Feitosa Rosas ${ }^{3}$, Caroliny dos Santos Guimarães da Fonseca ${ }^{4}$, \\ Luiz Felipe Ribeiro ${ }^{5}$, Ermelinda Maria Bernardo Gonçalves Marques ${ }^{6}$ \\ ${ }^{1}$ National Department of Distance Education, Estácio de Sá University, Rio de Janeiro, Brazil \\ ${ }^{2}$ Nursing Department, Fluminense Federal University, Niterói, Brazil \\ ${ }^{3}$ Nursing Department, Federal University of Rio de Janeiro, Rio de Janeiro, Brazil \\ ${ }^{4}$ Faculty of Health Sciences, European University of the Atlantic, Santander, Spain \\ ${ }^{5}$ Department of Information Technology, Federal University of Rio de Janeiro, Rio de Janeiro, Brazil \\ ${ }^{6}$ Health Department, Polytechnic Institute of Guarda, Guarda, Portugal
}

\section{Email address:}

renatajabour2014@gmail.com (R. J. Saraiva), geilsavalente@yahoo.com.br (G. S. C. Valente), spetra@ig.com.br (S. P. C. Sá), annmaryrosas@gmail.com (A. M. M. T. F. Rosas), enfcarolinyguimaraes@gmail.com (C. dos S. G. da Fonseca),

luiz.ribeiro@displace.com.br (L. F. Ribeiro), emarques@ipg.pt (E. M. B. G. Marques)

${ }^{*}$ Corresponding author

\section{To cite this article:}

Renata Jabour Saraiva, Geilsa Soraia Cavalcanti Valente, Selma Petra Chaves Sá, Ann Mary Machado Tinoco Feitosa Rosas, Caroliny dos Santos Guimarães da Fonseca, Luiz Felipe Ribeiro, Ermelinda Maria Bernardo Gonçalves Marques. Design Science Applied to the Virtual Support Method of the Nurse to Promote Mental Health for the Elderly and Their Caregivers. American Journal of Nursing Science. Vol. 7, No. 2, 2018, pp. 58-62. doi: 10.11648/j.ajns.20180702.13

Received: January 31, 2018; Accepted: February 24, 2018; Published: March 22, 2018

\begin{abstract}
The aim of this study was to present post-doctoral results, using the artificial intelligence, avatar robot "Vilma", as a tool for interaction between the elderly and their caregivers, with the intention to promoting quality of life. Action research, developed at the Health Care Center of the Elderly and its Caregivers (CASIC/UFF), Niterói, RJ, Brazil. Approval of the Ethics and Research Committee of EEAN/UFRJ (Plataforma Brasil) - under the number: 36876114.6.0000.5238. Participants: 28 caregivers, both formal and informal. Developed application by the design science method, suitable to the science of computing and health, for being compatible with activities related to support mental health and quality of life of the elderly, as a continuous operational support to the nurse, of a spiritual biopsychosocial nature. Use of the continuous operational support application as a tool to prevent depression, and the impacts of this pathology on quality of life. It was concluded that the research product tool was considered relevant by the participants for the teaching-learning process, in the search for mental health, self-realization, self-esteem and quality of life.
\end{abstract}

Keywords: Nursing, Elderly, Caregiver, Educational Technology

\section{Introduction}

Throughout the professional practice and teaching in the line of research on the elderly, psychological, affective and cognitive manifestations have been demonstrated, causing several physiological and mental consequences, which can lead to psychic suffering, depression and even

death of the elderly. Therefore, it has been identified as depression, one of the pathologies that most affect the elderly. 


\section{Depression and Mental Health of the Elderly}

\subsection{Depression}

Depression occurs more frequently, not only due to life circumstances (functional and social losses, acquisitive power, decreased adaptive capacity), but also due to the reduction of brain neurotransmitters, serotonin deficiency (5HT) - hydroxytryptamine, indolamine, resulting from the hydroxylation and carboxylation of the amino acid Ltryptophan, responsible for conduction of nerve impulses or use of drugs that accentuate depression, such as antihypertensives, tranquillizers and so on [1]. Therefore, the most commonly used antidepressants act to increase extracellular (5-HT) levels, the discovery of biomarkers that characterize more homogeneous subgroups of patients, is fundamental for understanding their pathogenesis and development of personalized therapies [2].

\subsection{The Mental Health of the Elderly}

The postdoctoral research of one of the authors allowed the implementation of specific therapeutic actions for health promotion and prevention of pathologies such as depression, using educational technology, through mental health workshops held at the Center for Health Care of the Elderly and their Caregivers (CASIC / UFF), Niterói, RJ, Brazil, from June to October 2017.

During the process, was verified the relevance of actions, using educational technology, used as a tool to help nurses, in relation to providing quality of life for the elderly and their formal and informal caregivers. As a foundation for the study, the global increase in life expectancy has led to reflection on the essential means to guarantee, in a satisfactory way, quality of life for the long-lived individual [3].

Thus, for this activity to be possible, a questionnaire was developed with questions related to the prevention of depression, with the aim of improving the process of approach by nurses and health professionals, involved in activities related to the elderly and their caregivers.

During the process, it was noticed that the return to feel alive, the pulse of the energy, the pleasure of the movement and the self-confidence, were renewing elements of the meaning of the life and the will to live, being fundamental for the spiritual biopsychosocial rehabilitation.

\section{Method}

It is an action research, using the design science method, aimed at solving problems from the application of new scientific knowledge, with the use of artificial technology in health. On this method, many paradigms of scientific research aim to discover "what is true", while the science of design seeks to identify "what is effective" [4].

For this reason, it was tried to follow the precepts of the method, since "the fundamental questions addressed by the research design science are:" how useful is this new artifact?", that is,"how much the artifact meets a need relevant? "and" what demonstrates this usefulness? [4].

Therefore, was sought to adapt the research to solve health problems of the elderly and their caregivers, specific to depression, in the search for mental health, self-realization, self-esteem and quality of life. There are many possible forms of artifacts to be developed in the field of science. It can be a method, a process, a questionnaire, an analytical formula, a scale for classification, among others [5].

Was chosen to use cognitive interaction workshops and the questionnaire, made available through artificial intelligence, involving a prototype, with the function of pre-test, to analyze the acceptance of the product as technological innovation, to give continuous operational support to the nurse of a spiritual biopsychosocial nature.

For that, a combination of artificial intelligence techniques (Avatar - Nurse Vilma) and machine learning was used, analyzing data from answers returned through access to the instrument by smartphones and/or tablets, after sending the link and online access request, obtaining 28 responses, which were analyzed by simple statistical percentage frequency. It is worth noting that the method used focuses on constant monitoring and identification of patterns that reflect habits, feelings and behavioral signs of the elderly, indicating suggestions for the best course of action, whether healthy or not.

For the analysis of the qualitative data, the sociological phenomenology of Alfred Schutz [6] was used, for addressing the importance and the use of methods that explore the maximum of the phenomena captured from the research. Their results are based on the real-life experiences of people with knowledge of the phenomenon on firsthand.

Phenomenology is a significant movement, initiated by Edmund Husserl in the early twentieth century in Germany, to describe that all consciousness is intentional and that no object is thinkable without reference to an act of consciousness, and that the presence of the object in the consciousness - evidence knowledge. Thus, knowledge is explained as fulfilling intention [6].

The study was approved by the Ethics and Research Committee of the Anna Nery School of Nursing - Federal University of Rio de Janeiro - UFRJ (Brazil Platform) - under the number: 36876114.6.0000.5238, in order to be the research inserted in the context of the thesis entitled "The sexuality of the elderly in the context of the nursing consultation: a phenomenological analysis", concluded in 2015.

As a scenario, the Center for Health Care of the Elderly and its Caregivers (CASIC/UFF), Niterói, RJ, Brazil, as a training camp for the workshops entitled "Mental Health of the Elderly and their Caregivers", in the May 22, 2017 through October 30, 2017, and as volunteer participants, 28 caregivers of the elderly, both formal and informal, according to the norms of Resolution 466/12.

It should be noted that the participation of these volunteers 
was only for the purpose of elaborating the instrument used as an online questionnaire, through the suggestions offered by them for the items to be compiled, not implying risks for those involved. After authorization from the health unit's management, the application activity was started to test the application and observe the results.

At the end of the research, a patent was filed for the method of continuous operational support, with the National Institute of Industrial Property - National Application for Invention, Utility Model, Certificate of Invention Addition and entry into the national phase of the PCT - Number of the Process: BR 102017020938 5, in October 2017.

During the post-doctoral internship, workshops were held with elderly people and caregivers, as described below, to support the implementation of the application, making use of the method of research design science and the phenomenological sociological Alfred Shutz methodology.

1st Stage - Actions taken from May 22, 2017 to August 4, 2017: Beginning of the workshops "mental health of the elderly and their caregivers" - held once a week - from 14:00 to 16:00 - educational lecture on "Thanatology." Discussion on the preparation of the questionnaire, data collection for elaboration of the research artifact creation (Nurse Vilma Robot) and playful closure. All participants were receptive to the research product presented.

Stage 2 - Actions performed from August 7, 2017 to September 26, 2017: Continuation of the workshops "mental health of the elderly and their caregivers" - held once a week - from 14:00 to 16:00 - educational lecture on "Psychological Aspects of Death; of dying and its symbolism. "In addition to, educational lectures with teachers and nurses invited, application test, conversation wheel and playful closure. All the participants showed interest and satisfaction in being part of the group.

Step 3 - Actions taken from October 2, 2017 to October 30, 2017: Continuation of the workshops "mental health of the elderly and their caregivers" - held once a week - from 14:00 to 16:00 - expositive educational class of "Ethical and bioethical aspects in the view of nursing, facing suffering and death; dysthanasia; euthanasia; orthatanasia and mistanasia. "Presentation of the application, as final research product, conversation wheel and play closure. The participants reported satisfaction with the final product presented and the relevance in the prevention of depression. They requested further research and new workshops.

\section{Results and Discussion}

Considering the specificity of the theme, it was decided to make use of the Sociological Phenomenology of Alfred Schultz to analyze the qualitative data. For this, it was necessary to listen to the participants, seeking their intentionality about quality of life, in order to understand the actions that drive the planning and execution of unique activities for each subject in this process. For better understanding, was chose to demonstrate these findings in tables.

Table 1. Biographical Data, Gender, Age, Income, Type of Housing. Gender $=$ Female 24 - Male $=04$. Niterói, RJ, Brazil, 2018.

\begin{tabular}{lll}
\hline Monthly Income & $\mathbf{N}$ & $\mathbf{\%}$ \\
\hline None & 3 & 10,71 \\
Less than 1 MW & 3 & 10,71 \\
$1-5 \mathrm{MW}$ & 11 & 17,86 \\
$6-10 \mathrm{MW}$ & 6 & 21,43 \\
$10 \mathrm{MW}$ or more & 5 & 39,29 \\
Total & 28 & 100,0 \\
\hline
\end{tabular}

\begin{tabular}{lll}
\hline Age Range & $\mathbf{N}$ & $\mathbf{\%}$ \\
\hline 18-24 years-old & 1 & 3,57 \\
25-35 yeras-old & 5 & 17,86 \\
36-50 years-old & 15 & 53,57 \\
51 years-old or more & 7 & 25,00 \\
Total & 28 & 100,0 \\
\hline & & \\
\hline Housing & $\mathbf{N}$ & $\mathbf{\%}$ \\
\hline Own with family & 18 & 64,29 \\
members & & \\
Rented with family & 3 & 10,71 \\
members & 5 & 17,86 \\
Own alone & 2 & 7,14 \\
Rented alone & 0 & 0 \\
Long-Term Institution & 24 & 100,0 \\
Total & 24 \\
\hline
\end{tabular}

*Note: MW - Minimum wage.

Source: data survey, 2018.

There was a higher number of women, in which $53.57 \%$ were in the 36-50 age group, with monthly earnings, mostly up to 5 minimum wages, living in the household with the family. Most houses in their children's homes, daughters-inlaw / grandchildren and grandchildren, reflecting the reality of the new Brazilian family.

It was observed in the workshops that the meaning of the previous family view refers to the possibility of help and approximation, corroborating the participants' speech, stating that, due to the change in the social role of the elderly, they verify, exactly the individuality of the members of the family cell and the isolation of the elderly.

The occurrence is due to the intercurrences generated by the structural dimensions, established among the various daily family contexts, that interfere in the quality of life of the elderly. Given the importance of the relationships between family life and the quality of life of its elements, it is pertinent to consider the family routine in the investigation of quality of life of the elderly [7].

Another Due to the reports of the caregivers and the analysis of the current situation, it is noticed that the change of the family cell would need to obey rules appropriate to the unique reality of each individual, with the purpose of achieving quality of life. However, in any situation, the elderly need a period of adaptation with the family, caregivers and their daily life. 
Table 2. Clinical Condition, Main Complaint, Religiosity, Violence, Use of Controlled Medication, Friendship Network. Niterói, RJ, Brazil, 2018.

\begin{tabular}{llll}
\hline Informed Pathology & $\mathbf{\%}$ & Violence - Have you suffered or suffered yet? & $\%$ \\
\hline None & $71.43 \%$ & Yes & $21.43 \%$ \\
Anxiety & $14.29 \%$ & No & $78.57 \%$ \\
Sadness & $3.57 \%$ & & \\
Depression & $10.71 \%$ & Use of Controlled Medication & $\%$ \\
Main Complaint - Uncontrolled & $\%$ & I did it once & $2.70 \%$ \\
Emotional & $60.71 \%$ & Never did & $56.06 \%$ \\
Physical & $21.43 \%$ & Short period & $18.50 \%$ \\
Mental & $10.71 \%$ & I currently do & $22.02 \%$ \\
Social & $7.14 \%$ & Friends Network & $\%$ \\
Religiosity & $\%$ & I think I have some & $28.57 \%$ \\
Yes - Practitioner & $35.71 \%$ & I do not have many & $14.29 \%$ \\
Yes - No Practitioner & $39.29 \%$ & I have few, but true friends & $32.14 \%$ \\
I do not know how to rate myself, but I believe God & $25.00 \%$ & & \\
\hline
\end{tabular}

Source: data survey, 2018.

Looking at the picture, one can see the frustrations generated by the structural change described above. The lack of reflection on the emotional emotions is evidenced when $71.43 \%$ affirm that they do not have any clinical problem, but they indicate as main complaint the emotional and mental uncontrolled.

They inform to fill this absence of affectivity in the religiosity, be it collective or individual, because $35.71 \%$ are practicing religious and $39,29 \%$ religious non practicing. Furthermore, through the analysis, all of them made or use controlled medication, demonstrating the need for emotional organization in the transition from family structural change.

Most respondents did not suffer violence, $78.57 \%$, showing again the lack of knowledge of their own feelings, as they report as a pathology anxiety $14.29 \%$, sadness $3.57 \%$ and depression $10.71 \%$.

Depression is a pathological condition, the consequences of which can be severe and disabling, and may interfere with the simpler aspects of everyday life. Therefore, it is understood that the elderly, because they are more vulnerable, will need more care, and it will be up to all concerned, family and society, to give due attention to avoid psychic suffering and depression [8].

It is understood with these results the importance of dissolving existing subjective boundaries through the experiences of the elderly and their families, legitimizing actions of self-knowledge in order to reduce risks and promote self-discovery in another phase of life, adjusting meanings capable of motivating the elderly to understand their new family and social role.

It is concluded by the analysis, resistance of the research participants in performing physical activity. Moreover, they do not understand leisure as a physical necessity for the organization of mental health. Of the 28 research participants, 12 responded to have moments of happiness, only 08 reported feeling good with their body and the same 12 that indicate having moments of happiness, reported having a restful sleep.

Therefore, it is observed that mental and physical disorganization affects the individual in its totality, contributing to the emergence of pathologies directly related to the quality of life. The analysis of the results of the caregivers made it possible to ascertain that the changes in physical and mental behavior among the elderly will favor active aging by including four types of components responsible for the reduction of risk factors for pathologies previously presented, such as anxiety and depression, these are: healthy food; decreased or no use of alcohol and tobacco; polypharmacy without medical prescription and pleasurable physical activity.

The anxiety and depression found in previous analyzes corroborate the results described. They demonstrate the fragility of participants' biopsychosocial status. Based on these data, the understanding of the new social role of the elderly, together with their family and society, is based on critical judgment, proving to be essential for attaining physical and mental health.

Through the intersubjectivity of those involved, it is necessary to establish actions with the intention of propitiating the teaching and learning of self-care aiming at the quality of active life of the elderly. The concept of quality of life is a comprehensive and multidimensional term, established from the understanding of the balance between physical health, psychological state, social relationships and the environment in which one lives [9].

The development of motivational skills, such as the use of educational health applications, helps to preserve the functionality of the elderly by preventing complications and minimizing risk factors for pathologies by performing activities that rehabilitate functional and mental capacity. With this, the elderly will have the maintenance of the functionality of their activities of daily living (ADLs) and, consequently, their independence.

\section{Conclusions}

With the end of the internship, the relevance of the use of the artificial intelligence, avatar robot "Vilma", as a tool of interaction between the elderly and their caregivers, was verified, with the intention of promoting quality of life.

The method adopted a holistic view regarding the biopsychosocial and spiritual model, based on humanization, with the intention of providing an active quality of life for the elderly. In addition to contributing to the improvement of the 
decision-making process of nurses working in activities related to the elderly.

Therefore, with the findings and with the deposit of the patent, a new stage of testing will begin, making use of sensors of the subsystem of artificial intelligence - cameras and depth sensors for creation of computer vision; microphone and keyboard for language processing; Chabot functionality; wearable devices; internal sensors such as GPS and motion sensors to detect the level of physical activity and real-time detection of falls.

Thus, the purpose of the study was to create perspective in the search for the transformation of old issues into new possibilities for understanding psychological phenomena, so important for the quality of active life.

\section{References}

[1] Xiang, J, Yan, S, Li, SH, Li, XJ. Postnatal loss of hap1 reduces hippocampal neurogenesis and causes adult depressive-like behavior in mice. PLoS Genetics. Vol. 11, No. 4, 2015, e:1005175.

[2] Rapaport, MH, Nierenberg, AA, Schettler, PJ, Kinkead, B, Cardoos, A, Walker, R, Mischoulon, D. Inflammation as a predictive biomarker for response to omega-3 fatty acids in major depressive disorder: a proof-of-concept study. Molecular Psychiatry. Vol. 21, No. 1, 2016, pp. 71-79.
[3] Pereira, DS, Nogueira, JA, Silva, CA. Quality of life and the health status of elderly persons: a population-based study in central sertão of Ceará. Revista Brasileira de Geriatria e Gerontologia. Vol. 18, No. 4, 2015, pp. 893-908.

[4] Hevner, AR, March, ST, Park, J, Ram, S. Design science in information systems research. Rev Mis $Q$. Vol. 28, No. 1, 2004, pp. 75-105.

[5] Sordi, JO, Azevedo, MC, Meireles, M. The research design science in Brazil according to publications in information management. Journal of Information Systems and Technology Management. Vol. 12, No. 1, 2015.

[6] Silva, WC, Silva, RM, Pereira, ER, Silva, MA, Marins, AM, Sauthier, M. Perception of the nursing team regarding oncologic palliative care: a phenomenological study. Online Brazilian Journal of Nursing. Vol. 13, No. 1, 2014, pp. 72-81.

[7] Marques, EM. Aging in the Guarda Council: a study on quality of life. [Thesis]. Doctoral in Universidad Pontificia de Salamanca.

[8] Frade, J, Barbosa, P, Cardoso, S, Nunes, C. Depression in the elderly: symptoms in institutionalized and noninstitutionalized individuals. Revista de Enfermagem Referência. Vol. 1, No. 4, 2015, pp. 41.

[9] Moraes, EL, Santos, MJ, Merighi, MAB, Massarollo, MCKB. Nurses' experience in the process of donating organs and tissues for transplantation. Revista Latino-Americana de Enfermagem. Vol. 22, No. 2, 2014. 